\title{
CRIANÇAS DO SERTÃO: MODOS DE VIDA. UM ESTUDO ETNOGRÁFICO DAS FAMÍLIAS DE SANTA CRUZ DO BANABUIÚ, CEARÁ
}

\author{
CHILDREN FROM THE BACKLANDS: LIFE STYLES. AN \\ ETHNOGRAPHIC STUDY ON FAMILIES FROM \\ SANTA CRUZ DO BANABUIÚ - STATE OF CEARÁ
}

Francileide Santana da Silva ${ }^{1}$

Maria Raquel de Carvalho Azevedo ${ }^{2}$

SILVA, ES.d.; AZEVEDO, M.R.d.C. Crianças do sertão: modos de vida. Um estudo etnográfico das familias de Santa Cruz do Banabuiú, Ceará. Rev. Bras. Cresc. Desenv. Hum., São Paulo, 11(1), 2001.

Resumo: Este estudo etnográfico é parte integrante da primeira etapa do projeto Lugar de Criança . Objetivou-se conhecer o modo de vida- organização familiar, as práticas culturais de cuidado das crianças na faixa etária de zero a sete anos e suas farnilias, ambos residentes no semiárido. Inicialmente foram visitadas 81 familias pertencentes a zona urbana e rural do distrito de Santa $\mathrm{C}^{\wedge}$ luz do Banabuiú, municipio de Pedra Branca. Em um segundo momento, 24 destas famílias foram revisitadas, entrevistadas e observadas, utilizando a metodologia de observação participante e diário de campo centrados no ambito familiar. As entrevistas foram realizadas com as mães, e as observações da familia seguiram um roteiro semi-estruturado. Percebeu-se a relação entre as práticas familiares e o ambiente de seca revelados no cuidado com a alimentação e higiene, a arquitetura das casas e nas falas da religiosidade popular. Frente à escassez de água, à baixa produção agrícola, aos empregos altamente rotativos e às questões de saúde, as familias criam suas próprias estratégias de convivência com o ambiente, cabendo à criança ajudar a familia.

Palavras-chave: família do semi árido brasileiro; práticas culturais; modo de vida.

\section{DESCRIÇÃO SÓCIO-DEMOGRÁFICA DA REGIÃO}

O trabalho foi realizado na área de abrangência de Santa Cruz do Banabuiú, popularmente denominada Cruzeta, localizada aproximadamente a $36 \mathrm{~km}$ da sede do município de Pedra Branca, Ceará. O distrito acha-se inserido numa área de semi-árido. A sua população estimada é de 3.784 habitantes, distribuída em 841 famílias.
Cruzeta possui acesso através de estrada carroçável. O transporte mais utilizado é o de carros de linha - caminhonetes D-20 e um ônibus, todos apresentando um certo desgaste. Cruzeta limita-se ao Norte com o município de Boa Viagem e ao Sul com o município de Tauá, a Oeste com o município de Independência, e a Leste com a sede do município.

Com a territorialização ${ }^{4}$ do município de Pedra Branca, realizada em 1997, a área de Santa

1 Cientista Social/UFC, pesquisadora da Escola de Saúde Pública do Ceará - ESP/CE e consultora da Federação de Bairros e Favelas de Fortaleza - FBFF, email: francileide.s@esp.ce.gov.br

2 Mestrado no Depto. de Sociologia/UFC, Coordenadora do Projeto Lugar de Criança e pesquisadora da Escola de Saúde Pública - ESP/CE, email: raquel@esp.ce.gov.br

3 O Projeto Lugar de Criança é uma iniciativa de trabalho conjunto entre a Escola de Saúde Pública do Ceará - ESP/ CE, a Fundação Bernard van Leer - BvLF e a Prefeitura Municipal de Pedra Branca - Ceará. O projeto em seu primeiro ano de atividades, propõe-se a conhecer o modo de vida das famílias no sertão e desvendar a repercussão do fenômeno da seca para o desenvolvimento infantil de crianças de zero a sete anos. Atuahnente, o projeto está discutindo a continuidade das atividades em parceria com a BvLF e a Prefeitura Municipal de Pedra Branca.

4 Mapeamento das localidades e sitios que compõem a área para efeito de abrangência da equipe de saúde da familia. 
Cruz de Banabuiú foi subdividida em 08 microáreas homogêneas: Mendes, Salgado, Riachão, Riacho, Feiticeiro, Coelho, Gameleira.

As principais dificuldades nos sítios e na sede são: falta de água, calçamento e energia. O distrito sofre também com ameaças de doenças, seca, insegurança por parte do trânsito, péssimas condições de conservação das estradas e falta de segurança pública.

O poder público buscou encontrar soluções para a seca, como no plano municipal participativo de desenvolvimento sustentável elaborado em 1999. Por este documento, a seca parece acarretar graves problemas sociais e econômicos, pois tanto a agricultura como a construção de açudes aparecem como prioridades a serem realizadas com a ajuda de parcerias junto ao governo do Estado no sentido da criação e geração de emprego e renda.

$\mathrm{Na}$ área de Cruzeta, as possibilidades de investimento identificadas por este documento foram a agricultura, a pecuária, a indústria e o comércio, chamando a atenção as aspirações das lideranças, tais sejam: construção de açude; mecanização agrícola; construção do novo posto de saúde; investimentos na pecuária; indústria de redes; mini indústria de confecção; mini indústria de calçados; ampliar policiamento (segurança); ampliar rede de comunicação (telefonia); tratamento de água; provisão mais abrangente de medicamentos; instalação de banheiros nas casas; instalação de dessalinizadores.

Em 29 de Dezembro de 1997, quando já implantado o Programa Saúde da Família, o município de Pedra Branca habilitou-se para Gestão Plena do Sistema Municipal de Saúde, o que representa uma maior autonomia na utilização dos recursos públicos para a saúde. Na ocasião, destacava-se, também, a obrigatoriedade na elaboração do Plano Municipal de Saúde, através de Oficinas de Territorialização que norteariam as metas estratégicas que o município viria a conduzir (SMS, 1998). As Oficinas de Territorialização passaram a ser realizadas a cada três anos, visando o melhoramento da cobertura das atividades nas áreas de abrangência dos PSF's.

No que tange à descentralização no nível "serviços e programas", o município conta hoje com dez equipes de saúde da família, visando uma cobertura de $100 \%$ da área de abrangência contando para isso com a colaboração de 89 agentes de saúde distribuídas entre a sede e os distritos do município (Minerolândia, Tróia e Santa Cruz do Banabuiú).
O município realizou a primeira Conferência Municipal de Saúde em 1992, sendo realizada em 1996 a segunda, e terceira em 1998, seguida da quarta Conferência Municipal de Saúde realizada em 11 de agosto de 2000. Essa conferência, com expressiva participação popular, resultou na atual composição do Conselho Municipal de Saúde, além de manter a criação dos Conselhos Distritais de Saúde com posse a ser realizada em Janeiro de 2001. A participação popular no âmbito do SUS Sistema Único de Saúde ${ }^{5}$ dá-se através dos Conselhos Locais e Conselhos Municipais de Saúde, órgão prioritário no controle social.

Para realizar essas atividades o sistema local conta com um hospital municipal (com 45 leitos e resolutividade nas clínicas médica, obstétrica, cirúrgica e pediátrica) e um centro de saúde, localizados na sede do município que funcionam ao mesmo tempo como porta de entrada do SUS, visto que o PSF ainda não abrange 100\% de cobertura no município.

\section{DESCRIÇÃO ETNOGRAFICA DO LOCAL}

O distrito de Cruzeta é, pois, a denominação popular do distrito de Santa Cruz do Banabuiú, sendo cortado pelas estradas que o ligam aos municípios de Boa Viagem, Independência e Tauá.

A primeira visão que se tem da vila (distrito-sede) são os quiosques que ficam às margens das estradas, formando um contorno colorido e alegre, onde crianças e adultos podem encontrar café, chá, bolo, ovos cozidos coloridos, além de lanches, sucos, água de côco e almoço. Esses quiosques ou barracas constituem-se em fonte de renda para algumas famílias residentes na vila, aonde trabalham adultos e crianças. Os pontos atendem às pessoas da comunidade e os viajantes, que passam com destino a outros municípios. Alguns comércios ficam abertos até a madrugada quando passam os últimos ônibus e alguns caminhoneiros. Os proprietárias das pequenas barracas são moradores que residem, em sua grande maioria, próximos aos quiosques.

Uma outra peculiaridade da sede do distrito é o modo como as casas são dispostas: sempre bem próximas umas das outras, na maioria parede e meia, chamando a atenção para a pouca privacidade entre as famílias, o que também pode possibilitar um sentido de vida comunitária, união ou cumplicidade. Assim, na vilapercebe-se que as famílias têm uma relação de proximidade, de compartilhamento do dia-a-dia.

5 O Sistema Único de Saúde é o sistema público de atenção à saúde prevalecente no Brasil. 
As fachadas das casas, em geral, possuem uma porta e uma janela de cor azul ou branca, em contato direto com a rua, não existindo muros, somente algumas calçadas e pequenos jardins com plantas da região e flores coloridas, que dão um tom agradável e alegre às residências. Essa paisagem colorida oferece uma acolhedora sensação na chegada à vila (cf. registro de observação de campo, 29 de julho de 2000).

Em frente às casas, ficam cisternas e tambores ligados ao telhado através de bicas feitas com canos de plástico, que servem para aparar a água da chuva. Estes depósitos de água têm duas funções: guardar a água das possíveis chuvas, e um outro, mais sistemático, de receber a água dos carros pipas que passam de duas a três vezes por semana. Assim, o modo de morar evidencia, desde logo, o cuidado e a preocupação quanto à água.

O abastecimento de água de Santa Cruz é realizado através de caminhões pipas, pertencentes a um vereador da comunidade local que a distribui conforme os recursos financeiros do usuário, ou seja, dependendo das condições econômicas do consumidor, o benefício possui um valor ou taxa a ser cobrada no ato do abastecimento. No caso de pessoas menos abastadas ou carentes, o recebimento da água passa a ser "um favor" retribuido com voto, gerando na comunidade a visão de que a água faz parte das suas obrigações, portanto, "errado é cobrar"6.

Em relação ao local de onde provém a água, as principais fontes são os pequenos açudes existentes na região, em número de 52 . Após ser coletada dos açudes, a água é depositada em tambores, baldes e bacias, que ficam expostas em frente às casas ou em cisternas públicas, facilitando o acesso a todos os moradores que não dispõem de tambores e cisternas em casa. Existem ainda outras fontes de recursos de água como: chafarizes (2), cacimbões (33), poços profundos (01), barragens (07) e rios (06), localizados na sede do distrito e em alguns sítios.

Entretanto, segundo as observações feitas e entrevistas realizadas junto aos moradores, mesmo com tantos recursos hídricos, não há provisão adequada para abastecer as casas e suprir a falta de água na região, até porque um número destes rios e açudes possuem águas impróprias ao consumo devido ao alto grau de salinidade. Além disso, sabe- se que o Ministério da Defesa Civil através do Comando Militar do Nordeste ( $1^{\text {a }}$ Região Militar 40 BI-Crateús) distribuiu água no último ano, o que foi suspenso em Outubro de 2000.

Além desta particularidade da água, em frente às casas existem tambores de lixo sempre cheios, tornando-se alvo das crianças e dos animais que, movidos pela curiosidade e pelo cheiro, começam a mexer nos detritos em busca de alimentos ou mesmo de algum objeto que lhes chame atenção, chegando a brincar com estes resíduos ${ }^{7}$.

O espaço urbano não é distribuído de forma a ocupar todos os espaços. Apesar da grande quantidade de casas vizinhas e agrupadas, existem muitos terrenos sem qualquer utilização, trazendo uma imagem de certo isolamento. Nestes locais, o mato cresce livremente e os resíduos plásticos se acumulam, entrelaçados às plantas rasteiras. Isso parece reforçar o cenário ou paisagem de "cruzeta", no meio de vias de grande movimentação, passagem de carros e pessoas, lugar de trânsito, e não de moradia ou estabelecimento de residências.

A vida das pessoas transcorre assim na vila, no meio desse trânsito de veículos. Inclusive quanto às famílias observadas, percebeu-se uma grande preocupação das mães quanto à insegurança das crianças brincarem fora das casas devido ao risco de acidente e morte, ordenando os filhos permanecer mais tempo no espaço interno ou imediato à casa.

Esse trânsito de pessoas e cargas parece trazer ao lugar (vila ou sede) a falta de proximidade ou identificação com qualquer um dos municípios que a circundam, criando uma imagem de abandono. Ao contrário, em relação aos sítios, a sede do distrito tem movimentação, social e religiosa bastante intensa, como se verá mais adiante.

Um forte motivo que leva as comunidades dos sítios a visitarem a sede do distrito é o período das festas religiosas, realizadas no mes de agosto, onde as pessoas participam das festividades através de novenas, caminhadas e leilões. Um outro motivo que também atrai "para a rua" ${ }^{\circ}$ os moradores dos sítios são os dias de feira e os de forró, quando grande quantidade de pessoas circulam na "rua" em busca de mercadorias para suprir suas dispensas ${ }^{9}$, ou atrás de diversão, caindo no forró no único clube do distrito.

6 Documento de Territorialização, 1997.

7 Durante as observações realizadas não se percebeu crianças ou adultos retirando objetos para alimentar-se. Entretanto, causou preocupação o fato das crianças brincarem com o lixo resultante das atividades do Posto de Saúde local, o que pode causar enfermidades. Em geral, as crianças brincam após saírem da escola, que está localizada do lado do Posto.

8 Ir para a rua é o modo como os habitantes das localidades identificam a sede de Cruzeta, o que sugere ser um local de grande movimentaçao.

9 Dispensa é o lugar onde são armazenados os alimentos nas casas. 
Apesar dessa movimentação social, recreativa, Cruzeta não dispõe de uma infra estrutura adequada a um distrito de seu porte, já que é constituído por muitas localidades e uma estimativa de mil e cem famílias residentes. O distrito não dispõe de rede de esgoto, tratamento de água e coleta de lixo adequados, e há a falta um destino final planejado, como um aterro sanitário, evitando-se assim que o lixo fique em contato direto com a comunidade.

Um outro fator que merece destaque é a pouca cobertura de energia elétrica na região, fato que obriga a população residente nas localidades próximas à sede a lançar mão de paliativos como o uso de lamparinas e lampiões a gás. Mas este não é um problema isolado dos sítios pois os poucos postes existentes na sede não são suficientes para iluminar a vila. A vida das famílias na sede de Cruzeta é quase sempre carente de uma melhor provisão de energia, devido às freqüentes, quase diárias, quedas de tensão. Faltam ainda as condições para a população fazer instalação elétrica em suas casas, devido ao alto custo deste serviço. Além destas carências, a comunidade sofre com a falta de transportes adequados, obrigando-os a fazer uso de camionetas, pequenos carros e ônibus clandestinos. Estes transportes circulam sem qualquer segurança nas estradas asfaltadas e carroçais que cortam o distrito.

Além desta escassez de recursos, a população carece de infra-estrutura voltada para o lazer, não dispondo de equipamentos sociais, contando com apenas uma praça, uma quadra de esporte e dois campos de futebol sem área verde. Estes locais apresentam péssimos estados de conservação; a praça, por exemplo, tem os bancos quebrados, piso deteriorado, apenas a televisão ${ }^{10}$ está em bom estado de conservação.

A televisão na vila (sede) só funciona no início da noite, sendo desligada à meia noite.
Muitos moradores ficam sentados nos bancos da pequena praça para assistir as novelas e os telejornais. Estes momentos de encontro dos moradores acontecem diariamente e lá são discutidos assuntos como violência, futebol, custo de vida e a vida dos artistas dentro e fora da novela. Alguns moradores mais exaltados chegam a discutir em voz alta, em defesa dos seus personagens prediletos. Nesses momentos, o clima beira a discórdia, alguns fumam, outros se exaltam e criam-se outras tramas para as novelas.

Os dois campos de futebol encontram-se cercados de mato e lixo. Afora estes locais, existe o monumento de cimento armado em meio ao cruzamento, que liga o distrito a outros municípios que, à noite, serve como ponto de namorados e motoqueiros.

Nos sítios ou localidades, o modo de morar das famílias revela uma imagem do isolamento real, poucas casas aqui e ali, não possuindo a mesma estrutura das casas da zona urban ${ }^{11}$. Seus prédios são mais antigos e, em sua grande maioria, encontram-se isolados ou quando agrupados, formam pequenas núcleos e/ou aldeamentos, existindo grandes espaços livres próprios para a criação de pequenos animais domésticos e cultivo de grãos e legumes. A1guns exemplos destes lugares são os sítios de Coelho, Gameleira, Cacimbinha, Bálsamo, Garapa, Condado e Tigre ${ }^{12}$.

A vida nos sítios é caracterizada pela criação de vacas, cabras e carneiros, pelo cultivo da terra como broca ${ }^{13}$, queima e plantio. Também faz parte da rotina das famílias as pessoas carregarem água em lombo de jumentos, na cabeça ou em bicicletas, utilizando ancas e borrachas de 20L. Afora isto, também é marcante o preparo da comida, cuidar das crianças e descansar no final do dia, reunidos na sala ou nos alpendres das casas. Desta forma, parece que, além de preocupar-se com o cultivo da terra e manter as orações em dia

10 A TV fica no meio da praça sobre uma estrutura de ferro, guardada em uma caixa igualmente de ferro.

11 Percebeu-se que o modo de morar das famílias na sede e nos sitios são antagônicos e extremos: enquanto não parece haver privacidade entre as famílias na sede, nos sitios as pessoas moram mais isoladamente. Existem barreiras físicas e geográficas dificultando a maior convivência.

12 Estas comunidades, com nomes tão característicos, possuem tais nomes - de famílias, plantas e animais - porque, no início da formação dos povoados, estes eram os nomes que identificavam estes lugares. Segundo alguns moradores, nas primeiras fazendas, as plantas predominantes na área, além dos engenhos de cana de açúcar e animais que se destacavam na região, acabaram por dar nome ás localidades.

13 Brocar, no linguajar sertanejo, tem o mesmo significado que “arrancar tocos”, isto é, planta-se, depois colhe-se, queima-se e, finalmente, prepara-se a terra retirando restos de raízes resistentes ao fogo: é “a limpa”. Depois da limpeza, a terra é semeada, reinicia-se o ciclo da vida para o povo do sertão. A prática do consórcio de culturas ao invés da queima não parece tão predominante, e é reconhecidamente um meio de cultivo da terra menos agressivo. 
para que o inverno seja bom e a terra fique fértil e viçosa produzindo uma boa safra, também faz parte da rotina de vida das famílias o lazer, muito restrito ao espaço externo da casa.

Nos sítios, não se percebe qualquer estrutura voltada ao lazer. Aos moradores dos sítios e localidades próximas como Salgado, Bálsamo, Feiticeiro, Coelho e Riachão, resta reunirem-se em casas de vizinhos nas calçadas ou em frente à televisão, em caso de sítios que já possuem energia elétrica. No restante dos sítios, a única fonte de lazer são as missas e cultos realizados nas Igrejas existentes no distrito. No caso das missas, nas quatro igrejas católicas, o calendário obedece às datas marcadas pelo pároco local. Quanto aos cultos evangélicos, acontecem geralmente aos sábados.

Apesar dessa feição puramente religiosa (no sentido de atribuir a Deus as dádivas de uma boa safra) também pode-se apreender a luta de alguns agricultores para organizar-se coletivamente, seja freqüentando escolas, participando de associações (moradores, produtores rurais) e sindicatos rurais, buscando, algumas vezes, atender necessidades pontuais como aposentadorias, implementos agrícolas como uso de tratores, ferramentas e, outras vezes, buscando conhecer os chamados “direitos de cidadania” no campo, reivindicando melhores condições de vida.

\section{A ORGANIZAÇÃO FAMILIAR}

A maioria das 24 famílias observadas são nucleares, constituídas por mãe, pai e filhos. Em geral, as mães concentram-se na faixa etária de 20 a 30 anos, com exceção de duas mães solteiras na faixa de 15-17 anos. Os pais têm de 20 a 40 anos ou mais, com exceção de três com idade avançada (em torno de 70 anos). A média de filhos é de dois a três filhos de zero a sete anos (Tabela 1).

As famílias são pouco numerosas, à exceção de algumas com muitos filhos em outras faixas etárias, além de famílias com mais de um núcleo, envolvendo avós, tios e outros parentes (25\%). Têm uma média de 06 (seis) moradores por casa. Nas 24 famílias, moram 151 pessoas, desse total, 60 são adultos ${ }^{14}$.

Não se percebeu, de modo geral, grande participação nessas famílias de agregados ${ }^{15}$, especialmente, sem vínculos de parentesco $(4,2 \%)$ (Tabela 2).
Os pais têm um baixo nível de escolaridade, 12 (50\%) são analfabetos ou cursaram de dois a três anos de estudo apenas (22 pessoas ou 92\%) (Tabela 4). Em grande número dessas famílias. os pais, mesmo provendo financeiramente o lar, estão mais tempo fora da casa do que as mães, trabalhando em outro distrito e, às vezes, em outro Estado (o Estado de São Paulo tem atraído grande número de trabalhadores da região). Nas famílias observadas, apenas três pais estavam ausentes de casa e da família (duas mães solteiras e uma união desfeita).

Tabela 1: Número de filhos de zero a sete anos por família.

\begin{tabular}{ccc}
\hline $\mathbf{N}^{\mathbf{0}}$ de Filhos & Freqüência & Percentual \\
\hline 01 & 07 & 29,2 \\
02 & 10 & 41,7 \\
03 & 02 & 8,3 \\
04 & 04 & 16,7 \\
05 & 01 & 4,2 \\
\hline Total & $\mathbf{2 4}$ & $\mathbf{1 0 0 , 0}$ \\
\hline
\end{tabular}

Tabela 2: Existência de agregados na casa.

\begin{tabular}{ccc}
\hline $\begin{array}{c}\text { Existência de } \\
\text { agregado }\end{array}$ & Freqüência & Percentual \\
\hline Agregado/Parente & 06 & 25,0 \\
Agregado/ & 01 & 4,2 \\
Sem parentesco & & \\
Sem agregados & 17 & 70.8 \\
\hline Total & $\mathbf{2 4}$ & $\mathbf{1 0 0 , 0}$ \\
\hline
\end{tabular}

Tabela 3: Escolaridade da mãe.

\begin{tabular}{lcc}
\hline Escolaridade da mãe & Freqüência & Percentual \\
\hline Analfabeta & 04 & 16,7 \\
$1^{\circ}$ grau incompleto & 13 & 54,2 \\
$1^{\circ}$ grau completo & 03 & 12,5 \\
$2^{\circ}$ grau incompleto & 03 & 12,5 \\
$2^{\circ}$ grau completo & 01 & 04,2 \\
\hline Total & $\mathbf{2 4}$ & $\mathbf{1 0 0 , 0}$ \\
\hline
\end{tabular}

Percebeu-se grande migração entre localidades, distritos e municípios vizinhos da região, pelas famílias observadas. Esse transitar pareceu bastante intenso pois algumas famílias estão fixando residência nos locais a menos de cinco anos (25\%), ao que parece devido a mudanças no trabalho, proximidade à família e condições de moradia (casas cedidas por familiares e necessidade do pai ausentar-se deixando a família junto de

14 Considera-se como adulto o jovem a partir de 20 anos.

15 Agregados: pessoas que moram na mesma casa com ou sem laços de parentesco. 
outros parentes). Alguns comentários durante as observações pareceram sinalizar o fato de um número de famílias ter se ausentado do distrito por certo tempo e depois retornar, o que poderia ser atribuído à identificação com o lugar de nascimento "para passar dificuldade, que se passe aqui mesmo” (observação de campo em 06/12/2000).

Maria Olinda ${ }^{16}, 34$ anos, residia na sede de Cruzeta há seis anos. Depois de retornar do Estado de São Paulo onde residiu durante três anos e meio e conheceu seu atual companheiro, gerou seus filhos e realizou alguns trabalhos temporários, como ela relata:

Tabela 4: Escolaridade do pai.

\begin{tabular}{lcc}
\hline Escolaridade do pai & Freqüência & Percentual \\
\hline Analfabeto & 08 & 33,3 \\
$1^{\circ}$ grau incompleto & 09 & 37,5 \\
$1^{\circ}$ grau completo & 07 & 29,2 \\
$2^{\circ}$ grau incompleto & - & \\
$2^{\circ}$ grau completo & - & \\
\hline Total & $\mathbf{2 4}$ & $\mathbf{1 ~ 0 0 , 0}$ \\
\hline
\end{tabular}

Tabela 5: Tempo de residência do pai.

\begin{tabular}{lcc}
\hline Tempo de moradia & Freqüência & Percentual \\
\hline Menos de um ano & 02 & 8,3 \\
De um a três anos & 03 & 12,5 \\
De 3 a 5 anos & 01 & 4,2 \\
De 10 a 15 anos & 02 & 8,3 \\
Mais de 20 anos & 08 & 33,3 \\
Não soube informar & 08 & 33,3 \\
\hline Total & $\mathbf{2 4}$ & $\mathbf{1 0 0 , 0}$ \\
\hline
\end{tabular}

“..trabalhei em firma e trabalhei na roça também (...) mas olha...eu arranquei feijão, eu catei laranjas, eu arr anquei 'colonial ', eu $f \mathrm{z}$ um monte de serviços...ai eu plantei todo tipo de serviço, apanhar algodão foi o melhor que eu achei na roça." (Entrevista em 23/11/2000)

Apesar de ter realizado vários tipos dá serviço e ter retornado a sua terra natal, ela comonta que outros lugares seriam bem melhorei do que Cruzeta, devido à possibilidade de emprego, bastante enfatizado na sua fala. A mãe revela o desejo de voltar a sair do Nordeste em busca de melhores condições de vida, onde possa encontrar emprego para ela e o marido mas, ao mesmo tempo, justifica sua perrnanêneia pelo fato de possuir pais já idosos e dois filhos pequenos (um casal de gêmeos de seis anos).

“... agora o que me leva eu a permanecer aqui, um é a questão dos meus pais e outro é

\begin{abstract}
a questão de sair pelo mundo com duas crianças pequenas, se torna muito difícil né? A não ser assim que numa cidade grande eu tivesse uma casa minha. Mas pra mim chegar assim, sem condição financeira para enfrentar a vida numa cidade grande, com duas crianças fica mais difícil, se fosse só eu, só a minha pessoa eu não estaria aqui, mas como eu tenho eles, eu achei por bem eu ficar aqui né. To aqui com eles no momento." (Entrevista em 23/11 /2000)
\end{abstract}

Lívia, outra moradora da sede do distrito de Santa Cruz, reforça em sua fala a necessidade de ocorrer a migração dos moradores do lugar para outros municípios ou Estados mas ressalta que os pais e companheiros ausentes fazem muita falta para as suas famílias. Essa mãe reforça a importância da questão afetiva e da falta da figura paterna na construção e desenvolvimento da família, de uma forma saudável, onde as crianças possam desfrutar do convívio com o pai usufruindo assim não apenas de alguns meses de convivência, mas de todo o acompanhamento do seu desenvolvimento.

\begin{abstract}
"Difícil assim, porque o serviço, o modo de trabalhar, precisa o marido sair pra longe, eu fico só, sofrendo com esse menino, sozinha né. E precisa ir prá São Paulo, né. E agora minha fílha tô ai com a minha filha doente, preciso ir pra Fortaleza, fico com meus filho abandonado aqui, só que o pai deles tá longe e justamente, também que água também é muito difícil também, a gente ir atrás de um balde d'água é a coisa mais difícil também, eu já pensei de sair, ir embora pra... pró ir a Pedra Branca, mas sozinha com eles eu sofro demais se eu for.!"
\end{abstract}

Além das dificuldades relatadas com a falta da figura paterna na distribuição das tarefas na hora de cuidar dos filhos, não se pode esquecer as dificuldades da convivência com a ausência de água no cotidiano das famílias do semi-árido e que, por muitas vezes, parece misturar-se no discurso das mães quando do relato da ausência dos pais. Ocorre uma junção das privações sofridas pela família no discurso dessa mãe, por exemplo, que parece considerar todas as dificuldades com o mesmo grau de importância. O sofrimento da privação de água, junto com a falta de melhores condições de vida, a distância algumas vezes de outros parentes e familiares, e a ausência do marido e pai dos filhos, aparecem na fala e expressões da mãe, no ato da entrevista, como um grande pesar em que ela não consegue identificar a causa principal.

16 Todos os moradores estão sendo apresentados utilizando-se nomes fictícios. 
Outras situações dramáticas também aparecem, evidenciando tentativas de alterar um cenário de privação ou necessidade. A experiência, a seguir, parece expressar esse fato. Davi, 49 anos, agricultor e morador de Cruzeta, relata o fato de, há dois anos atrás, haver participado de um bloqueio na estrada visando saquear caminhões carregados de alimentos. Seria essa prática comum na região? ${ }^{17} \mathrm{Na}$ opinião deste agricultor, a justificativa para este ato é que sua família estaria passando fome há mais de três dias. Na ocasião, teriam participado mais de trezentas pessoas, caminhando em direção à estrada, buscando encontrar caminhões de alimentos:

\footnotetext{
“Uns dois anos... foi do ano trasado para cá, até o ano passado nós... nós hoje não estamos assim de preparar uma coisa assim, né, mas está quase a mesma coisa, porque a necessidade é a mesma, ninguém tem legume para vender, ninguém tem ovelha, ninguém tem leite, ninguém tem pão para essas crianças, né, aí eu não vou fazer uma coisa tão errada assim, que eu sei que é errada, eu sair da minha casa me dirigir para uma fazenda, chegar lá e roubar eu não vou fazer isso, porque quem vai fazer esse tipo de coisa ele não está com necessidade, roubar, ele não está com necessidade, não é isso, ele está preparando uma coisa de prejudicar ele e outras pessoas, né, mas eu estou capaz... é eu vou parar por aqui, não dá mais para eu falar não. " (Vocês conseguiram parar algum caminhão de alimentos?) "Não, Sra.. não deu certo, nós paramos um caminhão de algodão. O rapaz chegou, ai quando nós falamos assim, eu não cheguei a falar não, o pessoal falou, ai ele foi e disse assim: "Pessoal, isso é uma carrada de algodão, agora se fosse alimento eu era capaz de sair fora aqui e ajudar a descarregar esse caminhão $e$ dar de comer a vocês, pois eu sou pai de família também e eu estou por dentro de tudo, sei o que é fome. O sofrimento que vocês estão passando, talvez seja a mesma coisa que eu passo, através desse grande aperreio que eu passei aqui." Porque o rapaz vinha muito veloz e quando riscou em cima, né, ele ficou nervoso, ficou se tremendo todinho no volante do carro e não sabia o que é que fizesse e aí nós dissemos para ele, eu fui uma das pessoas que disse, o Sr. não fique nervoso, porque ninguém vai tocar no Sr. nem com um dedo, nós estamos aqui através de alimento para os nossos filhos comer, hoje mesmo nós estamos com três dias que não come, era verdade que nós estava mesmo e aí aquilo ali não me saia da cabeça era eu... está lá naquele serviço lá e não conseguir trazer nada, como não trouxe, chegar e ver minhas crianças na mesma, né, como eu deixei. Então, a Sra. veja como tem pai de familia sofrido, eu dou de uns..." (Entrevista em 30/11/2000)
}

Esse agricultor fala das dificuldades, da falta de alimentos, da falta de trabalho e de assistência por parte do poder público no enfrentamento a precariedade da seca. Na sua opinião, mesmo com a instituição dos programas como frentes produtivas e distribuição de cestas básicas, não há uma melhora significativa nas condições de vida dessa população. Para ele, além da falta de critérios na alocação dos trabalhadores para o recebimento desses 'benefícios', ainda é grande a carência, seja de emprego, como de meios para promover a agricultura e produção. Além destas dificuldades o agricultor ainda faz menção à fome que a família vinha passando o que lhe causava grande angústia, desespero e tristeza por não ter como alimentar os filhos.

A melancolia e tristeza também parecem fazer parte da rotina da vida do sertanejo como pode ser visto em alguns romances nordestinos como, por exemplo, Vidas secas de Graciliano Ramos e $\mathrm{O}$ quinze de Raquel de Queiroz, onde o sertanejo é caracterizado por suas lutas, vitórias e sofrimentos seguindo o mesmo percurso da natureza com inverno e estiagem. Para Amadeu Amaral (1948, in FERREIRA, 1999), a tristeza do povo brasileiro deve-se não a uma característica que lhe seja peculiar, mas, ao contrário, à fome e às enormes dificuldades da vida. Como este autor comenta, “...em regiões que possuem clima saudável e economia decente, o matuto não é um fungo doente, um parasita miserável e infeliz, mas sim uma planta luxuosa e florescente” (p. 11).

\section{PRÁTICAS CULTURAIS DE CUIDADO}

\section{Religião}

No que se refere à religião o distrito possui calendário próprio onde são realizadas as novenas: das crianças, dos jovens, dos comerciantes, do vaqueiro, do funcionário público, do motorista, dos casais, dos visitantes e comunidades vizinhas e a festa do município. Durante estas atividades, toda a comunidade parece ser envolvida, através de caminhadas percorrendo o centro do distrito e as ruas próximas à Igreja. O cortejo tem uma duração de aproximadamente duas horas e é acompanhado por crianças, idosos e jovens, existindo ainda a participação das escolas locais e comerciantes. Também ocorrem missas, leilões e desfiles com a participação das autoridades locais: vereadores e prefeito. O mes de agosto é tido como o mes das novenas e das festas religiosas, quando as missas são celebradas diariamente pelo vigário mais antigo da região, co-

17 Esse fato nos instiga a tentar buscar informações para perceber se é prática comum naquela localidade ou região. 
nhecido como padre Geraldo, que há mais de 40 anos esta à frente da paróquia.

As crenças religiosas parecem relacionarse aos cuidados de saúde, pois a comunidade pára suas atividades para festejar seus santos protetores, pedindo proteção e cura para as suas enfermidades e ressaltando agradecimentos e louvores com orações.

Como visto em entrevistas, o discurso das mães aponta elementos religiosos, colocando seu destino e o dos filhos, nos desígnios de Deus:

\begin{abstract}
"Quando eu sai grávida dela, muita gente me dava conselho, "mulher, toma remédio, não sei o que e tal, tem injeção fulana de tal, quer tomar? "Não quero não, assim como eu pude ter os outros, Deus vai me dar espaço pra eu ter ela”. (...) "Quando Nosso Senhor bota um bom tempo. Até que é bom. Mas, se num. ... Num bota. Aí, a gente tem que trabaia muito". (... “Quando tão doente eu levo pru médico e pra rezar”.
\end{abstract}

Além disto, também se busca conforto diante das dificuldades recorrendo a algumas rezadeiras (14), onde são procuradas rezas, banhos, chás e ervas milagrosas, pondo em prática estas duas formas de manter os traços culturais locais. Assim, religião e cultura popular caminham juntas com um único objetivo: a cura e o bemestar do corpo e da mente.

A comunidade de Cruzeta busca encontrar na religião a resposta para a cura de seus males. Criando e santificando mitos que envolvem suas principais angústias: a falta de água e os parcos recursos na área de saúde. Desta forma, as pessoas elegem Santos milagreiros da própria comunidade e passam a fazer promessas e ex-votos ${ }^{18}$, creditando a estes as graças alcançadas.

Amaral Santos, morador de Cruzeta há 33 anos, "nasceu e se criou” ouvindo a mãe e as tias contarem os milagres das Cruzinhas. Ele mesmo se diz salvo por um dos milagres do Zé Martin.

"A história lá começou que o finado Zé Martin que era um cidadão que morava lá na propriedade e saiu pra caçar veado aí fez uma espera lá no pé de arueira butou os pauzinho lá e ficou lá em cima e deu sono ele caiu no chão lá e ele não morreu da queda, mas era muito desabitado lá, ainda hoje é, mas antigamente era mais. Mas ele não morreu no mesmo dia não, passou de uns quatro a cinco dias doente, sem morrer, não tinha costume de sair de casa e não voltar no dia, né, (...) ele já tinha morrido já fazia uns sete à oito dias que já tinha morrido, já

\begin{abstract}
estava bastante estragado, aí o pessoal sentiu muito, o pessoal, lá no local da onde ele morreu nasceu um oi daguinha, um olho d'água sem ver de que no meio do cerrado surgiu esse olho d'água. O pessoal começaram a orar lá, rezar por ele, não sei como foi que começou, surgiu, começou a fazer promessa, rezar, fazer um terço prá ele e tudo veio pra cá, os outros faz promessa pra ir tomar um banho com água das cruzinhas, traz garrafinha de litro pra molhar o rosto. Aí lá onde ele foi enterrado (...) construíram uma casinha, que neste tempo não tinha cemitério em canto nenhum e as outras pessoas, foram enterrando outras pessoas lá, né. Os anjozin que morria enterravam lá. E até hoje o pessoal continua nesse ritmo, faz promessa pra ficar bom da cabeça, de uma mão, ai eles faz um milagre, né, faz um milagre de pau, que chama, no meu caso fizeram a canela com os golpes e os pontos, ai a mãe foi lá, colocou lá. A gente chegando lá na casinha, tá lá, bastante braço, cabeça, mão, pé, tem corpo de gente, tudo lá, sabe, aquele mói que o pessoal coloca lá, sabe, e reza, faz suas promessas, toma um banho, reza e vem simbora. (...) Hoje, se for lá ainda existe o pé de árvore lá, a aroeira, muito grande, desgastada pelo tempo, mas os pauzim continua lá, atravessadim de uma forquilha prá outra, onde ele ficava."
\end{abstract}

Este morador de Santa Cruz do Banabuiú relata a história de uma das lendas mais populares da região, as “Cruizinhas”. Conta a lenda que o lugar onde morreu e foi enterrado o sr. Zé Martin, teria dado origem ao surgimento de um olho d`água milagroso ,que segundo os moradores, nunca seca nem mesmo nos períodos de seca mais longos. Este fato aguça o imaginário da comunidade que encontra nesta fonte de água não apenas a solução de abastecimento nos periodos de estiagem, mas também faz orações e promessas no local. Aparentemente, o Sr Arlindo é personagem de um mito religioso, onde a água é elemento central.

\section{Saúde}

As políticas de saúde no município de Pedra Branca têm privilegiado, nos últimos anos a adoção de algumas medidas de promoção, proteção e prevenção à saúde, destacando especial atenção à mulher, ao idoso e à criança. Entre essas medidas destacam-se as desenvolvidas no distrito de Santa Cruz do Banabuiú, onde o Programa de Saúde da Família atua. Para isso, o programa conta com a importante ação das agentes comunitários de saúde para desenvolver suas atividades junto à comunidade local, fazendo a cobertu-

18 Ex-votos são as partes do corpo que foi curada, eles são feitos de madeira e colocadas aos pés do Santo o qual se atribui a graça ou milagre alcançado. 
ra total da área de abrangência do Programa de Saúde da família (Quadro 1).

O Programa de Saúde da Família é um importante elemento do sistema local de saúde, pois busca abranger, com serviços básicos, essencialmente preventivos, toda a população do município, com ênfase na família.

Dentre as famílias observadas, amaioria das mães procura evitar que os filhos adoeçam buscando seguir as orientações das Agentes Comunitárias de Saúde em relação a fazer o pré-natal, a amamentação, colocar em dia o cartão da criança pesando e vacinando quando necessário, além dos cuidados de que se deve dar água e alimentos. As mães também procuram evitar que os filhos saiam de casa em horários de sol muito forte para que não venham a adoecer: "Não deixo brincar na terra quente. O maior problema da gripe, que andou dando ultimamente nas crianças. E a terra quente é ruim pra, gripe”. (...) "Não deixar ir pro terreiro Brincar com terra quente não butar porqueiro na boca”. (...) "Quando o sol ta quente eu não deixo ele sair pão sol". Para evitar que os filhos saiam nestes horários, as mães colocam as crianças para dormir após o almoço construindo uma prática de descanso após as refeições, evitando, assim, o contato com o sol forte nesta hora do dia.

Um outro tipo de prática desenvolvida nas famílias observadas se deve ao fato de estar ocorrendo um bom número de mães amamentando os filhos até o sexto mês de vida, desenvolvendo, desta forma, uma cultura de aleitamento materno. Algumas mães relataram que sempre que o filho adoece ou apresenta sinais de doenças recorrem a um agente comunitário, ao médico do PSF e à rezadeira, ao mesmo tempo. Este parece ser um fato muito comum nas famílias observadas, como já mencionado anteriormente. As mães parecem possuir assim três dispositivos de prática de cuidado com relação à saúde dos filhos recorrendo sempre que necessário.

Dentre as principais causas de doenças na região segundo as entrevistas e questionários realizados com 24 famílias estão as doenças sazonais como diarréia e infecto-respiratórias, além da desnutrição, que vem sendo combatida através de Programas de Combate a Desnutrição com a distribuição de leite e óleo às crianças desnutridas mas que parece ser ainda muito pouco diante de um quadro de miséria em que as famílias destas crianças estão inseridas.

\section{Educação}

No que se refere à situação das escolas, elas estão espalhadas entre a zona urbana e rural, sendo de Ensino Médio e Fundamental. Na sede do distrito, o ensino é realizado por duas escolas, uma delas especificamente com ensino voltado para crianças que vão desde a alfabetização a $4^{\text {a }}$ série (seriação e ciclos). Em relação à outra escola, o sistema é de ensino Fundamental e Médio, contando também com o Programa Tempo de Avançar (Fundamental e Médio), tendo este últi-

Quadro 1: Medidas adotadas pela Secretaria de Saúde na Ȧrea de Santa Cruz do Banabuiú.

\begin{tabular}{|l|l|l|}
\hline \multicolumn{1}{|c}{ Atenções implementadas } & \multicolumn{2}{c|}{ Medidas adotadas } \\
\hline Saúde da mulher & $\begin{array}{l}\text { Pré-natal, puerpério, Planejamento alvo } \\
\text { Familiar e Prevenção do câncer. }\end{array}$ & $\begin{array}{l}\text { Todas as mulheres em idade } \\
\text { fértil ou menor pausa. }\end{array}$ \\
\hline Saúde da criança & $\begin{array}{l}\text { Imunização, Avaliaça do Crescimento } \\
\text { e Desenvolvimento e Combate ás } \\
\text { Carências nutricionais. }\end{array}$ & $\begin{array}{l}\text { Todas as crianças da área de } \\
\text { abrangência do PSF. }\end{array}$ \\
\hline Saúde do idoso & Controle de Hipertensão e Diabete & $\begin{array}{l}\text { Idoso da área de abrangência } \\
\text { do PSF. }\end{array}$ \\
\hline Vigilância Epidemiológica sanitária & $\begin{array}{l}\text { Fiscalização dos Abates e } \\
\text { Armazenamento da Carne.Controle de } \\
\text { Zoonozes. }\end{array}$ & $\begin{array}{l}\text { Abatedouros clandestinos e } \\
\text { vacinação de animais } \\
\text { domésticos (cães e gatos). }\end{array}$ \\
\hline CRUTAC (Centro de treinamento e \\
ação comunitaria). & $\begin{array}{l}\text { Estagio para estudantes universitários } \\
\text { dos cursos de Medicina, Odontologia, } \\
\text { Farmácia e Enfermagem. }\end{array}$ & $\begin{array}{l}\text { Comunidade de Cruzeta, } \\
\text { através de atendimento } \\
\text { realizado no posto de saúde e } \\
\text { visitas domiciliares. }\end{array}$ \\
\hline Programa de Agente Comunitário & $\begin{array}{l}\text { Este programa faz parte do PSF e tem } \\
\text { por objetivo divulgar e levar } \\
\text { informações a comunidade sobre saúde } \\
\text { e melhoria na qualidade de vida. }\end{array}$ & $\begin{array}{l}\text { Toda a comunidade de } \\
\text { Cruzeta com visitas } \\
\text { periódicas,visando a qualidade } \\
\text { de vida da comunidade: }\end{array}$ \\
\hline Saúde bucal & $\begin{array}{l}\text { Consultório odontológico no posto de } \\
\text { saúde }\end{array}$ & \begin{tabular}{l} 
Sem atendimento atualmente. \\
\hline
\end{tabular}
\end{tabular}


mo a obrigatoriedade da participação das Agentes Comunitárias de Saúde que não possuem o nível médio.

No caso de alguns sítios, existem Escolas de Ensino Fundamental as quais possuem o sistema de Seriação e Ciclos e, muitas vezes, funcionam de forma precária, em prédios antigos ou casas cedidas por algum fazendeiro. Devido ao pequeno número de sítios com escolas, há casos de grupos de crianças que chegam a percorrer cerca de $3 \mathrm{~km}$ a pé até chegar ao ponto de encontro dos carros que fazem o transporte escolar, em direção à sede do distrito.

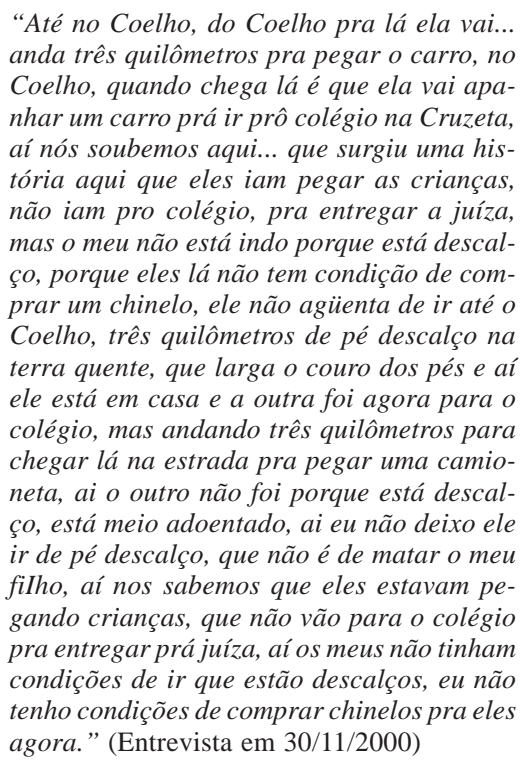

As famílias observadas demonstram um cuidado muito grande em relação ao encaminhamento das crianças para as escolas, relatando as dificuldades que os filhos têm que enfrentar para chegarem ao seu destino. Embora exista um sistema de transporte, as áreas onde residem as crianças não são totalmente cobertas por estes serviços, obrigando algumas crianças a percorrerem aproximadamente cerca de $3 \mathrm{~km}$ até o local onde apanham o transporte. Além deste fato, um outro que merece destaque é o tipo de transporte utilizado pelos alunos, que são obrigados a fazer uso de caminhonetes, colocando assim suas vidas em risco. Através deste cuidado, os pais demonstraram o desejo de que os filhos possam ter um futuro melhor e não apenas se submeterem a trabalhar na agricultura, na terra “dos outros”.

Existe, além desta preocupação com a educação formal, o cuidado de repassar os costumes e modo de vida da comunidade de geração a geração, ou seja, de pais para filhos, onde os valores culturais e as tradições são mantidos buscan- do, desta forma, não se perder o vínculo entre o antigo e o moderno. Isto foi percebido através das observações feitas nas 24 famílias, sendo possível detectar algumas formas desta manifestação, seja através do cuidado dispensado ao armazenamento da água e dos alimentos, ou ainda através de retratos com motivos festivos com fotos de casamentos e balizados espalhados nas paredes, misturados aos de santos e times de futebol, e também na maneira como as refeições são distribuídas, seguindo a ordem de importância e colocação na árvore genealógica da família, ou ainda pelo fato de alguns pais fazerem a distribuição de tarefas entre as crianças, tomando como ponto de partida o sexo e a idade dos filhos para cada tarefa dispensada aos mesmos.

\section{AS CASAS E SEU AMBIENTE INTERNO}

O ambiente interno das casas não difere muito entre a zona urbana e a rural quanto à demonstração de fé: os dois tipos de moradores preservam a mesma forma de enfeitar e distribuir nas paredes da sala, retratos de família com datas comemorativas e imagens de santos e pequenos altares com direito a velas e terço. Além disto, uma outra forte semelhança entre as casas urbanas e rurais se deve ao cuidado dado à água de beber, que geralmente fica exposta na sala em potes de barro recobertos por toalhinhas de croché ou pequenas guardanapos pintados à mão, possuindo ainda copos de alumínio reluzentes que podem ser vistos sobre os potes presos por pregos na parede.

Em relação aos outros espaços das casas, dois merecem destaque: o número de quartos e os objetos neles expostos, tais como redes, camas e muitas caixas de papelão que parecem suprir a necessidade de cômodas (mais visto nos sítios).O outro espaço é a cozinha, onde podem ser vistos fogões a lenha e a gás (sede), além das baterias de panelas arcadas. Um outro fato comum nas duas moradas se deve ao fato de existir o costume de guardar pedaços de carne seca tais como vísceras de suínos, caças, presos entre os caibros da cozinha. Também se vêem tábuas nas paredes, na sala e cozinha, ornamentados com flores, feitas com material reciclado de plástico para exposição de pontes, escovas de dente e copos acima dos potes, com água para consumo próprio. Os potes sempre aparecem de forma destacada pelo cuidado.

As diferenças entre os dois tipos de ambiente começam a surgir com relação ao número de divisões existentes na casa: enquanto na sede se observa a existência de um maior número de cômodos destinados a quarto, o mesmo não acontece nas casas dos sítios, onde muitas vezes toda 
a família divide o mesmo quarto na hora de dormir. Um outro fator de diferenciação, está relacionado àquestão dailuminação e umidade das casas: enquanto na sede as casas apresentam uma maior iluminação e claridade, um certo arejamento do ambiente, o mesmo não ocorre nas casas dos sítios, onde muitas vezes se percebeu o forte cheiro de $x i x i$, além da umidade e da penumbra predominante no ambiente.

São, portanto, os cômodos internos das casas: sala (depósito); quartos: poucos, cama de casal, muitas redes; quartos diferenciados (meninas e meninos) ou quartos juntos, poucas vezes arrumados; cozinha: fogão à lenha, fuligem nas paredes, casinhas para guardar objetos, panelas brilhando (paneleiras); bacia com água para lavar louças; mesas de pau cheias de mantimentos.

\section{Higiene}

O sistema de limpeza das casas, na comunidade estudada, depende exclusivamente da mulher, cabendo a esta realizar os mais variados tipos de cuidados com a casa, tendo para isso que desenvolver atividades domésticas, que vão desde varrer, lavar louças, roupas, apanhar água e cuidar do preparo dos alimentos.

A grande maioria das casas não dispõe de boa estrutura no tipo de material utilizado na sua construção, o que só vem a dificultar a sua limpeza e conservação, sendo, em muitos casos, construídas de barro e possuindo piso também de barro batido, o que dificulta a realização de uma boa higiene nas casas. Além disso, boa parte das casas observadas, também não dispõem de banheiros com aparelhos sanitários e fossas sépticas, utilizando o mato próximo às residências para as necessidades fisiológicos, comprometendo, desta forma a saúde e a qualidade de vida das famílias, que são obrigadas a lançar mão desta prática.

Em relação à limpeza pública, só é realizada na zona urbana, sendo o lixo colocado em tambores coletados duas vezes por semana. Seu destino final é a céu aberto, uma vez que é jogado a dois quilômetros da sede. Além desta manutenção dispensada aos dejetos, existe também a queima realizada semanalmente. Outro fato constatado é a ausência de sistema de esgoto, existindo somente o sistema de fossas e vala negra, o que parece contribuir para a pouca higiene nas casas estudadas, cabendo às famílias encarregarem-se pessoalmente do destino dado à sua produção de lixo.

A higiene pessoal é demarcada, visivelmente, pela dificuldade de água, visto que os moradores se utilizam de pequenos açudes próximos às suas casas. A vida passa a ser rasa na ausência de água e é construída pela aridez fertil da terra, marcada nos seus corpos empoeirados, nos rostos e mãos calejados, nos pés descalços e nas faces marcadas pelo semi-árido. As roupas recordam retalhos remendados, quase sempre surrados e marcados pelo tempo de uso. Apesar disto, roupas penduradas nas cercas contradizem as imagens visíveis através do próprio corpo dos moradores. Elas simbolizam o esmero e a lavagem, apesar dos pesares, de suas vestimentas pessoais. Dentro das casas, uma presença na penumbra, mesmo de dia, de redes e colchas encardidas e com cheiro forte de urina e suor. As roupas são acondicionadas nos poucos cômodos, em caixas de papelão embotadas.

As teias de aranha registram os espaços do telhado e das paredes. Elas tecem uma prática cultural peculiar na arquitetura das casas, como adereços e enfeites tão necessários quanto retratos antigos, santos, relógios de parede e rostos de artistas de televisão. Convivem em harmonia com a poeira das vigas nos tetos, interligando-se às garrafas de dois litros repletas de cereais, dispostos na parte superior das meias paredes na sala das casas. O chão, quase seinpre de barro batido e, algumas vezes de cimento alisado, repetem a matéria-prima com que são feitas as habitações. Também a familiaridade e a convivência com o ambiente quase natural, em consonância com o semi-árido, representam uma perfeita extensão com o lado de fora dos lares. Por mais que as casas sejam limpas, varridas, elas convivem diariamente com a presença de animais que transitam deixando sinais, através de penas, cheiros e fezes. Essa é a higiene interna das casas.

De um modo resumido, quanto à pratica cultural dada ao lixo, registrou-se: botar no mato: varejar fora de casa sem preocupação com o destino final e um local adequado; lixo orgânico reaproveitado para alimentação de animais (porcos, cabras, galinhas); fezes demarcam o espaço externo da casa, sem preocupação nenhuma por parte dos moradores; embalagens e plásticos desbotam o cenário natural, comprometendo o equilíbrio ambiental - poucos resíduos são absorvidos pelas crianças em suas brincadeiras - a produção desses resíduos é maior que o aproveitamento.

Quanto à água: para beber: pote / pano / altar / às vezes fervida / hipoclorito (ACS) Copos sobrepostos nas prateleiras. Retiram a água diretamente do pote com o copo (cada um tem o seu); para banho: açude; para cozinhar: buscam em cisternas próximas (quando há) / cuícas / baldes / latas; crianças ajudam como podem - criança construiu uma cacimbinha de barro e colocou água - promessa de água - convivência com a sua condição de escassez.

Quanto à convivência com animais: soltos como crianças / os enjeitadinhos (cabras e 
burricos) de criação representam animais domésticos que são criados dentro de casa e amamentados pelas crianças e pelas donas de casa; animais cuidados dentro de casa: galinhas empoleiradas na cozinha e chocas em quartos dentro de caixas e pondo na cozinha; domésticos: alguns gatos e cachorros são vistos dentro de casa junto às crianças; animais de criação: cabra, porco, galinha, capote, peru, pato, ovelhas, vacas (poucas); presença de currais e chiqueiros, mas os animais ficam muitas vezes soltos e as crianças utilizam esse espaço para brincar.

\section{DIVISA O DOS PAPÉIS FAMILIARES}

A maioria dos pais tinha como atividade principal a agricultura, além de pequenos serviços temporários como carpintaria, carroceria (transporte de cargas) e pecuária que parecem resultar, na maioria dessas famílias, em renda direta de menos de um salário mínimo mensal. Em geral, essas atividades obedecem a uma remuneração na forma de diárias ou “empreita”19, no caso de trabalhador avulso (prestador de serviço) e pagamento mensal no caso de trabalhador de fazenda (caseiros).

Diante das dificuldades econômicas decorrentes do período de estiagem, algumas famílias são cadastradas no programa de distribuição de cestas básicas e alguns pais no programa de frentes produtivas ${ }^{20}$. Em geral, os pais costumam passar mais tempo fora do espaço da casa, estando na roça ou à procura de trabalho. Um outro destaque se dá à existência de pequenos comércios locais, com venda de bebidas e sereais vindo de outros municípios. O funcionalismo público é o responsável por grande parte da economia que circula no distrito. Também é notório o fato das mulheres complementarem a renda familiar com o feitio de croché.

As mães, mesmo identificando-se em sua maioria como agricultoras, têm como atividade básica as atividades domésticas: são donas de casa. Em geral, as mulheres possuem uma escolaridade superior ao homem (analfabetismo 16,7\%, 33\% respectivamente). A divisão de tarefas no espaço da casa reserva á mulher um grande número de atribuições.

Durante as observações, os pais puderam ser encontrados rapidamente no início da manhã ou no horário de almoço, dividindo as tarefas domésticas com a esposa e filhos mais velhos no que diz respeito ao transporte de cargas d’água, lenha para fogão e outras atividades. A definição das atividades próprias aos homens e às mulheres chama a atenção, pois esses serviços mencionados são também executados por mulheres, enquanto tarefas como cozinhar, limpar, lavar e cuidar das crianças em geral cabem apenas às mulheres, com exceção de famílias onde a mãe é ausente e o cuidador principal é o pai, aparecendo, neste caso, a figura da avó, tias e outros familiares a ajudar com as crianças. Como comentado em entrevistas, os pais, em geral, ajudam no cuidado com as tarefas domésticas especialmente durante o período de “resguardo" das mulheres, também provendo cuidados com a mulher gestante e o recém-nascido. No mais, algumas mulheres entrevistadas chegaram a comentar que eles ajudam mais “cuidando” (leia-se: provendo) da família, ainda que a mulher, muitas vezes, tenha um papel complementar na provisão de recursos (também cuida da roça da família e realiza pequenos serviços como costura, artesanato de croché etc.).

A grande maioria das famílias tem na mãe o suporte maior na hora das atribuições de tarefas diárias como o preparo de alimentos, higiene da casa e limpeza de roupas, além de outras tarefas, como descrito. A mãe parece mostrar um certo grau de satisfação em desempenhar os dois papéis, de cuidadosa e provedora de recursos. Além disso, a mulher parece preparar os filhos maiores para cuidar dos filhos menores e envolvê-los nas tarefas domésticas, tornando claro para os filhos as tarefas próprias a serem desempenhadas por cada um na comunidade. Como exemplo disto, tem-se a menina orientada a cuidar dos irmãos menores (dando banho, alimentando, ninando, entre outras coisas), enquanto o menino carrega água e busca lenha.

Assim, cada criança é orientada de acordo com a sua idade e sexo, desempenhando o papel do gênero e ressaltando, desta forma, os aspectos culturais da comunidade.

\section{O ALIMENTO}

As famílias do semi-árido têm como alimento principal os grãos: arroz, feijão e milho.

A situação econômica da região está baseada na agricultura de subsistência, sendo cultivado: milho, feijão, fava, mamona e algodão. O cuidado com o alimento parece ter um significado especial para a cultura local: o ritual do plantio, armazenamento e preparo é traço comum à comunidade. O feijão parece ser o abre-alas das refeições; é, em geral, o primeiro a ser preparado

19 Significa que o pagamento total é acordado no ato do início do serviço, independente do tempo a ser dispendido.

20 Não foi percebido o número de pessoas cadastradas recebendo esses recursos dentre as famílias visitadas. 
e não pode faltar na mesa das famílias, enquanto a carne ou peixe parece ceder lugar à galinha. $\mathrm{O}$ milho, de uso versátil, serve a várias funções, desde alimentar até servir como objeto de brincadeiras. Não parece existir diferenciação de alimento entre crianças e adultos, a não ser em se tratando de crianças menores (menos de um ano, até perto de dois anos). Além disso, ocorre, em quase todas as casas, uma organização por sexo idade e função que o membro desempenha na família, na hora da distribuição das refeições: geralmente a mãe começa a entrega dos pratos feitos a partir do pai, seguido do filho mais velho, mantendo assim uma hierarquia familiar e ressaltando o papel e a importância do chefe da família.

Além do plantio que obedece a épocas diferentes, o armazenamento é uma prática comum, realizado de três maneiras: em tubos de zinco, garrafas plásticas e sacas de $50 \mathrm{~kg}$. Geralmente, as garrafas plásticas são encontradas até como enfeites ou ornamentação da casa, dispostas nas "paredes e meia” que ligam os cômodos entre si nas casas.

Outras garrafas de vidro também servem de depósito de grãos durante grande período de tempo, vedadas com cera de abelhas, tarefa realizada por toda a família, inclusive pelas crianças. Além dos grãos, a farinha de mandioca é outro alimento utilizado e que serve a dieta do sertanejo.

Uma família transmitiu falta de recursos materiais e financeiros, percebida de duas maneiras: uma, através da aparência desnutrida das crianças, além das vistas opacas e olhares tristonhos, o choro freqüente das crianças, além da fala das mesmas "eu tô com fome mãe, bota o almoço”. Esta casa foi observada durante o horário intermediário, que teve início no fim da manhã seguindo o começo da tarde, das 11:30 às 14:30, horário esse que seguindo os padrões usuais de hábitos culturais e alimentares, seria o almoço, seguido de repouso das crianças menores. Fato que não ocorreu. As crianças ficaram pedindo comida, no que só foram atendidas por volta das 14:00 quando, segundo a mãe, achou um real que procurava desde o horário da manhã dentro de uma caixa e mandou o filho mais velho à mercearia para comprar um saco de pão. Quando chegou, foi recebido com festa pelos irmãos que fizeram uma fila com prato na mão para receber das mãos da mãe o pão e, em seguida, sentaramse no chão formando rodinhas.

MONTENEGRO (2000) comenta, discutindo o imaginário do homem nordestino na convivência com o ambiente das secas, algo que parece relacionar-se com essas observações quanto ao esmero das famílias no armazenamento de viveres: "As plantas ensinam os habitantes a viver; guarda as tuas reservas e sobreviverás às secas. As plantas xerófilas sobreviveram durante séculos, com 34 secas, porque elas gostam deste solo e deste céu como eles são. Por não aprender essa lição, é que os matutos olham para o céu ou rezam para chover” (p.34).

Este relato ilustra a força deste ensinamento nestes brasileiros moradores do semi-árido que lá sobrevivem há várias destas 34 secas, contando, basicamente, com as suas próprias reservas, sociais e humanas.

\section{CONSIDERAÇÕES FINAIS}

Entende-se por estratégia de sobrevivência a capacidade de enfrentamento das famílias às dificuldades da vida no contexto do semi árido, que podem ser percebidas desde a alimentação (pouca variabilidade de alimentos, produção limitada e cíclica restrita à subsistência), o cuidado com a água (poucos recursos hidrícos), assim como o trabalho, a educação e a saúde.

A partir das observações realizadas, identificaram-se algumas soluções criadas pelas famílias no sentido de conviver melhor com as adversidades da vida no seu ambiente fisico e sócio-econômico, que parecem significar estratégias de sobrevivência diante da seca e da pobreza como se vê no quadro 2.

\begin{abstract}
This ethnographic study integrares the first stage of lhe project Lugar de Criança (Child’s Place). It aimed at investigating Lhe way of living, lhe family organisation, and lhe cultural practices related to lhe care that is given to children between zero and seven years of age and their families, ali of them living in lhe Brazilian semi-arid region. Initially, lhe project team visited 81 families living in the urban and rural zones of the district of Santa Cruz do Banabuiú, municipality of Pedra Branca. In a second stage, 24 of these families were visited again, interviewed and observed, using the methodology of participating observation and field diary, centred on the family scope. The interviews were carried out with the mothers, and the family observations followed a semi-structured script. The authors perceived a relationship between the family practices and the drought environment, revealed in the careful practices of feeding and hygiene, in the architecture of the houses and in the discourse of popular religiosity. Faced with lack of water, low agricultural production, highly rotating jobs and health issues, the families create their own strategies to live in that environment, and the child must help the family.
\end{abstract}

Key-words: family from the Brazilian semi-arid region; cultural practices; way of living. 
Quadro 2: Dificuldades percebidas e soluções criadas pela família.

\begin{tabular}{|c|c|}
\hline Dificuldades percebidas & Soluções criadas pelas famílias \\
\hline $\begin{array}{l}\text { Falta de } A g u a \text {, escassos recursos hídricos, alto grau } \\
\text { de salinidade nos pequenos açudes e riachos }\end{array}$ & $\begin{array}{l}\text { Armazenamento sem tratamento adequado, } \\
\text { diferentes tipos de cuidado e prioridade na utilização } \\
\text { A arquitetura das casas favorece o acúmulo de água } \\
\text { das chuvas }\end{array}$ \\
\hline Pouca diversidade de Alimentos e produção cíclica & $\begin{array}{l}\text { Armazenamento de grãos em grandes quantidade s } \\
\text { para consumo próprio, carne seca, vísceras e caças } \\
\text { (pequenos animais do mato) como recursos } \\
\text { alimentares }\end{array}$ \\
\hline $\begin{array}{l}\text { Economia baseada na agricultura, poucos tipos de } \\
\text { serviço e oportunidades de trabalho }\end{array}$ & $\begin{array}{l}\text { Empregos temporários e de baixa qualificação com } \\
\text { alta rotatividade, saida dos trabalhadores para } \\
\text { municípios e localidades vizinhas e outros Estados }\end{array}$ \\
\hline $\begin{array}{l}\text { Ocorrência de doenças (doenças sazonais como } \\
\text { diarréia, infecções respiratórias e desnutrição) }\end{array}$ & $\begin{array}{l}\text { Visitas a rezadeiras com utilização de remédios } \\
\text { caseiros e adoção de práticas religiosas (rezas, } \\
\text { simpatias) } \\
\checkmark \text { Visita aos profissionais de saúde da família, } \\
\text { inicialmente as agentes comunitárias e } \\
\text { posteriormente aos médico e enfermeiro }\end{array}$ \\
\hline $\begin{array}{l}\text { Ausência de atividades e equipamentos próprios ao } \\
\text { Lazer }\end{array}$ & $\begin{array}{l}\text { Formas de lazer diferenciadas entre a sede e os } \\
\text { sítios: } \\
\text { * Cruzeta sede: televisão comunitária, praça, } \\
\text { comércios locais, Igrejas e festas religiosas, } \\
\text { festas recreativas; } \\
\text { * Sítios: alpendres e varandas das casas, visita a } \\
\text { casa de vizinhos, Igrejas }\end{array}$ \\
\hline $\begin{array}{l}\text { Necessidade da mãe ser provedora de recursos e } \\
\text { cuidadora }\end{array}$ & $\begin{array}{l}\text { Crianças a partir dos cinco anos começam a cuidar } \\
\text { dos menores na ausência da mãe bem como ajudar } \\
\text { nas tarefas domésticas }\end{array}$ \\
\hline Educação & 02 escolas de nivel médio \\
\hline
\end{tabular}

\section{REFERÊNCIAS BIBLIOGRAFICAS}

BRANCO, Ad.M. Mulheres da seca; luta e visibilidade numa situação de desastre. João Pessoa: UFPB, Ed. Universitária, 2000.

FERREIRA, J.Ad M. Tradições ruralistas. João Pessoa: Editora Universitária, UFPB, 1999.

GOMES, A.M. Imaginário social da seca, suas implicações para a mudança social. Recife: FUNDAJ, Editora Massangana, 1998.

MELO NETO, J.C.d. Morte e vida severina. $34^{\mathrm{a}}$ ed. Rio de Janeiro: Nova Fronteira, 1994.

MONTENEGRO, A.F. Psicologia do povo cearense. Fortaleza: Casa de José de Alencar / Programa Editorial, 2000.
RAMOS, G. Vidas secas. São Paulo: Record, 1999.

SCHEPER- HUGHES, N. Death without weeping: the violence of everyday tifo in Brazil. Berkeley: University of California, 1992.

QUEIROZ, R.d. O quinze. São Paulo: Siciliano, 1993.

Recebido em 20/06/2001

Modificado em 20/07/2001

Aceito em 20/08/2001 